\title{
Remição de pena pela leitura - Uma abordagem transdisciplinar de multiletramentos para a construção da cidadania desejáve1
}

\author{
Remition of pena by reading - A transdisciplinary approach of \\ multiliteracies for the construction of desirable citizenship
}

Angela Brambilla Cavenaghi Themudo Lessa ${ }^{1}$

Grassinete C. de Albuquerque Oliveira ${ }^{2}$

\section{Resumo}

O objetivo do artigo é apresentar e discutir um projeto piloto de leitura e escrita para mulheres adultas em situação de privação de liberdade desenvolvido por Pesquisadores do Grupo de Pesquisa ILCAE. O projeto visa a trabalhar com a leitura em uma perspectiva pedagógica de multiletramentos que impliquem na construção de uma cidadania como uma atividade desejável. Desenvolvido como uma pesquisa na área de Linguística Aplicada transdisciplinar de base crítica, apresentamos primeiro a parceria estabelecida entre a Penitenciária Feminina da Capital e a Fundação São Paulo/PUC-SP. A seguir, delimitamos o escopo desta pesquisa no bojo dos

${ }^{1}$ Professora Titular da Pontifícia Universidade Católica de São Paulo - PUC-SP; Docente Permanente do Programa de Estudos Pós-Graduados em Linguística Aplicada e Estudos da Linguagem - LAEL; Linha de Pesquisa: Linguagem e Educação; Líder do Grupo de Pesquisa Certificado pelo CNPq: Inclusão Linguística em Cenários de Atividades Educacionais ILCAE; Editora do Periódico: The Specialist e Diretora da Faculdade de Filosofia, Comunicação, Letras e Artes.

${ }^{2}$ Graduada em Letras: Português-Espanhol, pela Universidade Federal do Acre, UFAC (1999); especialização em Psicopedagogia, pela Faculdades Integradas de Várzea Grande FIAVEC (2002) e mestrado em Letras - Linguagens e Identidades, pela Universidade Federal do Acre - UFAC (2009). Atualmente é professora da Universidade Federal do Acre (UFAC). As linhas de interesse estão relacionadas às questões de Linguística Aplicada ao ensino de Língua Nacional e às abordagens dos gêneros discursivos no ensino de língua nacional. Doutora em Linguística Aplicada e Estudos da Linguagem, pela PUC-SP.

Interfaces da Educ., Paranaíba, v.11, n.32, p. 466 - 488, 2020 
princípios estabelecidos pelo trabalho. Finalmente, discutimos os resultados parciais encontrados no projeto piloto obtidos e os novos encaminhamentos traçados.

Palavras-chave: Leitura e Escrita. Multiletramentos. Educação. Privação de Liberdade.

\begin{abstract}
The aim of this paper is to present and discuss a pilot reading and writing project for women in a situation of deprivation of liberty developed by researchers from the ILCAE Research Group. The project aims to work with reading in a pedagogical perspective of multiliteracies that imply the construction of a citizenship as a desirable activity. Developed as a research in the area of critically based transdisciplinary Applied Linguistics, we first present the partnership established between the Capital Women's Penitentiary and São Paulo Foundation/PUC-SP. Next, we delimit the scope of this research within the principles established by the work. Finally, we discuss the partial results found in the pilot project and the new guidlines to be followed in the research.
\end{abstract}

Keywords: Reading and Writing. Multiliteracies. Education. Deprivation of Liberty.

\title{
Introdução
}

O ato educativo resume-se em humanizar o ser humano (Arendt, 1988)

Em vistas de compreender que o ato de educar envolve considerar o outro com todas as suas singularidades, de percebê-lo como sujeito partícipe, que munido de experiências vivenciadas (re)significam o mundo, buscando transformá-lo, a leitura e a escrita, no contexto de privação de 
liberdade, prendem-se dinamicamente na compreensão de que é preciso estimular e valorizar o conhecimento das participantes e colaborar para promover novas conexões de aprendizagens.

A compreensão do texto lido, pelos princípios freirianos, implica em uma leitura crítica que consegue relacionar o texto e o contexto vivido a uma significação concreta, profunda sobre o que é lido e, em seguida, escrito. A leitura envolve uma "arqueologia" (FREIRE, 1989, p. 13) complexa sobre o ato de ler e a experiência existencial do leitor, em busca de uma melhor compreensão sobre o texto lido.

Com essa proposta, em primeiro plano, apresentamos o projeto firmado entre as duas instituições, Presídio Feminino da Capital e Fundação PUC-SP, o método desenvolvido, participantes e a coleta de dados. Em seguida, discorremos sobre a estrutura das oficinas desenvolvidas. Em continuidade, na análise do projeto piloto, discutimos algumas das contradições, dos conflitos encontrados. Por fim, apresentamos as considerações finais.

\section{$O$ projeto firmado e uma perspectiva in- e transdisciplinar}

O projeto é parte de uma parceria firmada entre uma Penitenciária Feminina da Capital (PFC) e a Fundação São Paulo que, ancorada na Portaria no. 7/2016, do Poder Judiciário, do Tribunal de Justiça do Estado de São Paulo, datada de 01/06/2016, estabelece como objetivo geral o artigo $1^{\circ}$ instituir, no âmbito da $\mathrm{PFC}$, a possibilidade de remição de 4 dias de pena para cada livro lido e resenhado.

A Portaria, assinada pelos Juízes de Direito da Unidade da $1^{\text {a }}$. Região Administrativa Judiciária do Departamento Estadual de Execuções Criminais, parte dos pressupostos de que (a) a leitura é um trabalho intelectual que se equipara ao estudo e que (b) contribui no processo de reinserção social das custodiadas, pela capacidade de agregar valores éticomorais à sua formação, estabelecendo então a possibilidade de instituir a remição de pena pela leitura. 
Estabelece, também, parâmetros para (a) a participação das internas no projeto, (b) os procedimentos a serem seguidos desde o início das oficinas que serão oferecidas às reeducandas (c) a escrita de uma resenha a ser avaliada e corrigida pela equipe da PUC e (d) o posterior envio das produções escritas à Corregedoria dos Presídios da Unidade da $1^{\text {a }}$. Região Administrativa Judiciária do Departamento Estadual de Execuções Criminais. É na Administração Judiciária que é efetuada a contagem de tempo para fins de remição, segundo critérios estabelecidos na Portaria Conjunta no. 276, de 20 de junho de 2012, do DEPEN.

Segundo o a Portaria que rege a parceria acordada entre as duas instituições, os objetivos específicos de conteúdo são:

Verificar a compreensão de leitura e escrita das reeducandas e produzir o registro de leitura da obra lida demonstrando os seguintes aspectos:

- Apreensão do tema;

- Levantamento das ideias principais;

- Pontos relevantes para as reeducandas;

- Reflexão crítica.

Deles decorrem os objetivos específicos da forma, quais sejam:

- Estética -respeitar parágrafo; não rasurar; respeitar margem; letra cursiva e legivel;

- Limitação ao tema - limitar-se a resenhar somente para conteúdo do livro, isto é, não citar assuntos alheios ao objetivo proposto;

- Clareza/compreensão - demonstrar na resenha, que compreendeu o conteúdo da obra;

- Fidedignidade - proibição de resenhas que sejam consideradas como plágio.

A proposta baseada na Portaria 7/2016 trazida para a Fundação São Paulo foi analisada pela Direção da FAFICLA que convidou pesquisadoras dos Programas de Língua Portuguesa (PLP), Linguística Aplicada e Estudos da Linguagem (LAEL) e Literatura e Crítica Literária (LCL) para participar. Todos mostraram-se interessados em atuar na parceria e, conforme 
mencionado anteriormente, o Grupo de Pesquisa Inclusão Linguística em Cenários de Atividades Educacionais (ILCAE) do LAEL deu início à pesquisa.

Aproveitando a oportunidade de entrar no Sistema Carcerário oferecido pala Secretaria da Administração Penitenciária do Estado de São Paulo, decidimos que o trabalho de pesquisa e intervenção a ser desenvolvido deveria ultrapassar as fronteiras de um estudo na área de ensino-aprendizagem de Português segundo os parâmetro por eles estabelecidos, conforme consta da Portaria. Como pesquisadores da área de Linguística Aplicada, pautamos nossa pesquisa no desenvolvimento das capacidades linguísticas estabelecidas na Portaria para que a reeducandas possam ter 4 dias de remição de pena para cada livro lido e resenhado, conforme esperado pela proponente do trabalho conjunto.

Entretanto, nossa meta é expandir essa competência técnica do uso de ferramentas de práticas letradas, ou seja, saber usar o letramento de letras como discutem Rojo (2012) e Custodio (2013). Nesse sentido, estabelecemos como objetivo desta pesquisa de extensão trabalhar com a leitura em uma perspectiva pedagógica de multiletramentos que impliquem na construção de uma cidadania como uma atividade desejável.

Os pilares teóricos que dão sustentação ao trabalho de pesquisa se entrelaçam em uma perspectiva interdisciplinar e transdisciplinar, segundo Moita Lopes (2006). É interdisciplinar pois articula aspectos teóricos e metodológicos da área da Linguística Aplicada, da Educação e da Sociologia. A transdisciplinaridade é garantida pela postura investigativa que teoriza novos saberes e constrói soluções sócio-historicamente situadas.

Da linguística aplicada, trabalhamos com o conceito de pedagogia de multiletramentos que enfoca a questão identitária e de diversidade no ato de leitura do mundo, ou seja, das atividades de atribuir sentidos partilhados em sociedade. A leitura nessa perspectiva é uma prática de construção de conhecimento social, em oposição a um fenômeno individual. Segundo Cope e Kalantzis (2008), o conhecimento não se trata de um fenômeno individual, mas sim social. Nesse sentido, a língua que nos constitui apresenta marcas do que aprendemos com as pessoas com as quais convivemos desde Interfaces da Educ., Paranaíba, v.11, n.32, p. 466 - 488, 2020 
crianças. Somos assim participantes ativos nas práticas sociais letradas das quais participamos.

No contexto deste estudo, mais do que trabalharmos com a visão de leitura mais tradicional, unidirecional e monolitica que encara o texto escrito como uma representação da verdade conforme Signorini (2009) critica, concentrar-nos-emos nas atividades de multiletramentos conforme proposta do New London Group e, especificamente, nas discussões de Cope e Kalantzis (2000) que trazem a diversidade, o conflito, o outro, já que os valores e princípios são a base dessa pedagogia.

Da área da Educação, concordamos com Gentili (2001), que diz ser a educação da cidadania um requisito fundamental para a consolidação e o desenvolvimento de uma sociedade mais justa e democrática. Contudo, o autor afirma ser necessário questionar como educação, cidadania, direitos, justiça e democracia se articulam, pois há questões conceituais e ideológicas de base que fundamentam essa tecitura. Segundo ele, é necessário compreender que tipo de educação deve orientar nossas práticas e que cidadania devemos almejar.

No contexto desta pesquisa, de educação de adultos em situação de privação de liberdade, podemos inferir que é, segundo a Portaria 2/2016, um trabalho intelectual de reinserção social de remição de pena. As bases norteadoras do trabalho a ser desenvolvido com as reeducandas é de base formal e estrutural calcadas em uma concepção de língua padrão.

Contudo, conforme explicamos anteriormente, entendemos que o objetivo estabelecido deve ter suas fronteiras alargadas em uma visão transdisciplinar que permita capacitar as reeducandas não somente a fazer uma leitura dos livros selecionados e elaborar uma resenha dentro dos moldes fixados pela Secretaria Penitenciária, mas principalmente, promover a construção de novos espaços de conhecimentos.

Entendemos que por meio de uma leitura na abordagem de multiletramentos, romperemos com os estudos tradicionais de linguística e trataremos de problemas críticos com que se defrontam a sociedade, 
conforme dito por Celani (2006), pois entendemos que seremos mediadores de mudanças.

Retomando Gentili (2001:70), o projeto trabalha com o conceito de cidadania não só como condição legal por meio da redução de pena das reeducandas segundo os aspectos linguísticos descritos, mas temos como foco a cidadania como atividade desejável. Constatamos que, na perspectiva da Secretaria de Administração Penitenciária, as oficinas de leitura e de escrita permitirão que as detentas sejam reconhecidas como pertencentes a uma comunidade política na qual são portadoras de direitos (condição legal). Fazendo referência à proposta do inglês T. H. Marshall, são as condições históricas que permitem a extensão da cidadania para a esfera social mediante os direitos à educação, ao bem-estar, à saúde e ao trabalho. Parece-nos que essa é a perspectiva de cidadania e educação como direito humano estabelecido para a população carcerária feminina.

Por sua vez, Onofre e Julião (2013:51) reconhecem que a educação na prisão se configura como uma política pública que enfrenta desafios e cujo objetivo é dotar o homem aprisionado de conhecimentos, valores e competências que the permitam reconhecer-se como sujeito de direitos. Tal visão é consonante com a compreensão de cidadania expressa pela Secretaria da Administração Judiciária, ou seja, é considerada como um direito concedido pelo estado. Contudo, conforme exposto anteriormente, nossa proposta é que seja considerada como prática desejável, como aspiração radical de uma vida emancipatória.

Concordamos com Onofre (2015:1) ao argumentar que "nos espaços prisionais é fundamental a escuta de pessoas que são silenciadas pelas normas do sistema e abrir espaços para as narrativas de vida é dar-lhes oportunidades de saber-se no passado presente". Entendemos que a cidadania desejável deve ser construída socialmente como um espaço de valores e de instituições nas quais se garantem condições efetivas de igualdade que permitam o mútuo reconhecimento dos sujeitos como membros de uma comunidade de iguais (GENTILI, 2001). 


\section{Método desenvolvido}

Trata-se de uma pesquisa interpretativa qualitativa segundo conceituada por Denzin e Lincon (2006), pois envolve uma abordagem interpretativa do mundo que, neste caso, significa que estudaremos nossas práticas realizadas no contexto educacional do sistema penitenciário. Tentaremos entender os significados que as reeducandas e pesquisadores atribuem às atividades de leitura e escrita em uma abordagem de multiletramentos. Por meio da análise das contribuições dos atores sociais implicados chegaremos aos significados atribuídos e reconstruídos em nossas interações.

A abordagem qualitativa parte do pressuposto de uma relação dinâmica entre o mundo real, concreto e o sujeito, sendo que essa interdependência viva faz com que ocorra um vínculo indissociável entre o mundo objetivo e a subjetividade do sujeito (CHIZOTTI, 2001), de modo que o sujeito-observador é parte integrante do processo do conhecimento e interpreta os fenômenos detectados no objeto, atribuindo significados.

A pesquisa se inscreve no paradigma crítico pois concordamos com Kincheloe e MacLaren (2006) que argumentam que Educação e Linguagem representam práticas sociais que se constituem e são constituídas por fatores econômicos, sociais e políticos. Nesse sentindo, a compreensão de tais fatores pode abrir espaços para reflexões e ações críticas orientadas para transformações sociais. De acordo com Moita Lopes (2006), a abordagem crítica propicia uma reflexão acerca de situações reais de uso da linguagem, que expande os limites das teorizações da vida social na direção de sua problematização e mudança.

\section{Participantes da Pesquisa}

A equipe de participantes da pesquisa conta com pesquisadores com diferentes tipos de envolvimento. Temos um coordenador geral que articula as discussões, um doutorando que atua como professor das oficinas realizadas no presídio, duas doutorandas que participam das aulas e fazem anotações seguindo os princípios da etnografia (não temos permissão para 
gravar dados), e um grupo maior de mestrandos e doutorandos que participam das discussões contribuindo com críticas e sugestões.

Ressalte-se que os doutorandos (o que atua como professor e as que participam das aulas com anotações) procuram captar o universo das percepções, das emoções, das interpretações dos sujeitos participantes da pesquisa, em seu contexto. À medida em que partilham das experiências, mantêm uma conduta de detectar os problemas apresentados durante as oficinas e reformular estratégias dos obstáculos detectados, a fim de reconstruir adequadamente as ações propostas.

\section{Coleta de dados}

Segundo cronograma de trabalho apresentado à Coordenadoria de Unidades Prisionais do Governo do Estado de São Paulo, ofereceremos 5 oficinas para trabalharmos com:

- leitura de obras disponiveis no acervo da Biblioteca do Carandiru e a escrita de resenhas seguindo as orientações de base linguística por eles estabelecidas;

- acompanhamento produção de resenhas;

- correção das resenhas produzidas pelo grupo de pesquisadores responsáveis As resenhas produzidas ao final são corrigidas pelo grupo a partir de critérios (a) estabelecidos pela Portaria e (b) e por nós responsáveis pelo processo em uma perspectiva da formação de cidadania legal e atividade desejável.

- encaminhamento para a Diretoria do Centro de trabalho e Educação da PFC.

O projeto foi apresentado aos Comitês de Ética da Secretaria Prisional e da PUC-SP e fomos informados pelo primeiro que gravações em áudio e vídeo são proibidas por questões de segurança. Mediante tal dificuldade, optamos por realizar registros etnográficos de campo, ou seja, um de nós conduz as oficinas e os demais, além de auxiliarem no desenvolvimento das atividades, fazem as anotações da maneira mais detalhada possivel. 
Após cada oficina, realizamos encontros de discussão a respeito das anotações. Concluindo, além dos dados obtidos nas atividades do cronograma, obtemos importantes registros sobre o processo da construção da cidadania ética nos quais valores, normas e práticas, e não apenas direitos, constituem uma prática educativa, cidadã e desejável.

A formação da cidadania supõe a possibilidade de criar espaços educativos nos quais os sujeitos sociais sejam capazes de questionar, de pensar, de assumir e, também, é claro, de submeter à crítica os valores, as normas e os direitos morais existentes, inclusive aqueles tidos como mais democráticos e justos.

\section{Estrutura das oficinas}

Para cada obra selecionada, oferecemos um ciclo com 5 oficinas com a duração de duas horas. Participam delas as reeducandas selecionadas pela Direção da Penitenciária Feminina. Além dos aspectos linguísticos estabelecidos pela Portaria, trabalharemos com os seguintes movimentos pedagógicos propostos por Cope \& Kalantzis (2000) concernentes aos multiletramentos, prática situada, instrução evidente, enquadramento crítico e prática transformadora.

Entendemos, com base nos autores, que é mediante às práticas situadas que pertencem à cultura das reeducandas, que é possível estabelecer relações com outras práticas tais como as que elas esperam se inserir quando deixarem o presídio. A instrução evidente, vem a ser a análise dessas práticas, a fim de atribuir a elas interpretações e significados vigentes. Quanto ao enquadramento crítico, procuramos interpretar os contextos sociais e culturais das práticas de leitura, para que as reeducandas possam olhar criticamente para si mesmas e, em seguida, por meio de uma prática transformada, reconstruam significados tomando como norte outros contextos nos quais irão se inserir após cumprir pena. 


\section{Análise do Projeto Piloto}

Consideramos que o projeto piloto serviu como aprendizagem para que observássemos como funciona o sistema prisional no tocante à remição de pena pela leitura. Para que alcançássemos os objetivos propostos seria necessário uma análise profunda em relação ao que foi coletado, principalmente aos problemas detectados e que não atenderam aos objetivos propostos, já que buscamos no movimento dos multiletramentos, na prática situada presentificadas pelas reeducandas, uma perspectiva transformadora.

Ao apresentar os documentos para o Comitê de Ética - PUC e para o Sistema Prisional, a autorização para realizar gravações, tirar fotografias ou filmar ficou sob análise e iniciamos o projeto sem esses instrumentos para a coleta de dados. Diante deste aspecto, os registros foram realizados por três participantes que fizeram a anotação de campo. Revelamos uma crítica no tocante ao tipo de registro de coleta de dados. Essas anotações foram orientadas diante das experiências anteriores de cada um dos participantes, de seus olhares, crenças e valores, o que tornou dificil tecer um texto que fosse analisado de maneira mais objetiva possivel.

Diante desse aspecto, as nossas reflexões demonstraram que a etnografia foi fundamental para o nosso entendimento do cenário, das ações dos participantes e dos objetos de pesquisa. Particularmente, permitiu-nos ver o que é e como se faz educação em uma situação adversa, com as condições que nos foi apresentada, na realidade vivida pelas reeducandas no sistema prisional.

Conforme apresentado acima, o projeto foi desenvolvido em uma sala de aula, dentro do presídio feminino da cidade de São Paulo, com aproximadamente 25 reeducandas, com diferentes idades - entre 20 a 50 anos - e escolaridades, do Ensino Fundamental I ao Superior. Esses encontros ocorriam às quintas-feiras, das $15 \mathrm{~h}$ às $17 \mathrm{~h} 30 \mathrm{~min}$. O grupo de pesquisadores chegava às $14 \mathrm{~h}$, passava pela revista e se dirigia à sala da coordenadora pedagógica do presídio para apresentar o que seria discutido e buscar o equipamento de Datashow que era utilizado durante as aulas. 
Devido as reeducandas trabalharem dentro do presídio, dificilmente as aulas iniciavam às $15 \mathrm{~h}$, já que precisavam da autorização da agente para que se deslocassem para a sala de aula. A liberação delas era algo que sempre era negociado entre a equipe do presídio e o professor-pesquisador. Elas também comentavam sobre a demora na liberação, mas nada podiam fazer.

Em relação aos livros, foram escolhidos três títulos pela coordenação pedagógica do presídio, tendo em vista a coletânea existente na biblioteca. É importante ressaltar que a nossa perspectiva era, de modo colaborativo com as reeducandas, definirmos a obra que tivesse maior relevância e afinidade para escrever a resenha. Entretanto, desconhecíamos a realidade do sistema prisional, as normas de distanciamento, as regras em relação aos procedimentos didáticos, aos cuidados com o recolher todo o material utilizado nas oficinas, ao fato das reeducandas não poderem participar do planejamento, pois se estavam presas é porque praticaram alguma infração, conforme exposto pela Diretora do Presídio e Coordenadora Pedagógica. Todos esses fatos colaboraram para a revisão desse procedimento.

Em vista dessa regulação e mediante a apresentação das três obras escolhidas, procuramos deixar as reeducandas folhearem os livros e comentarem sobre o que mais chamava a atenção, por que e qual das obras gostariam de ler. Os livros resenhados no projeto piloto foram: 

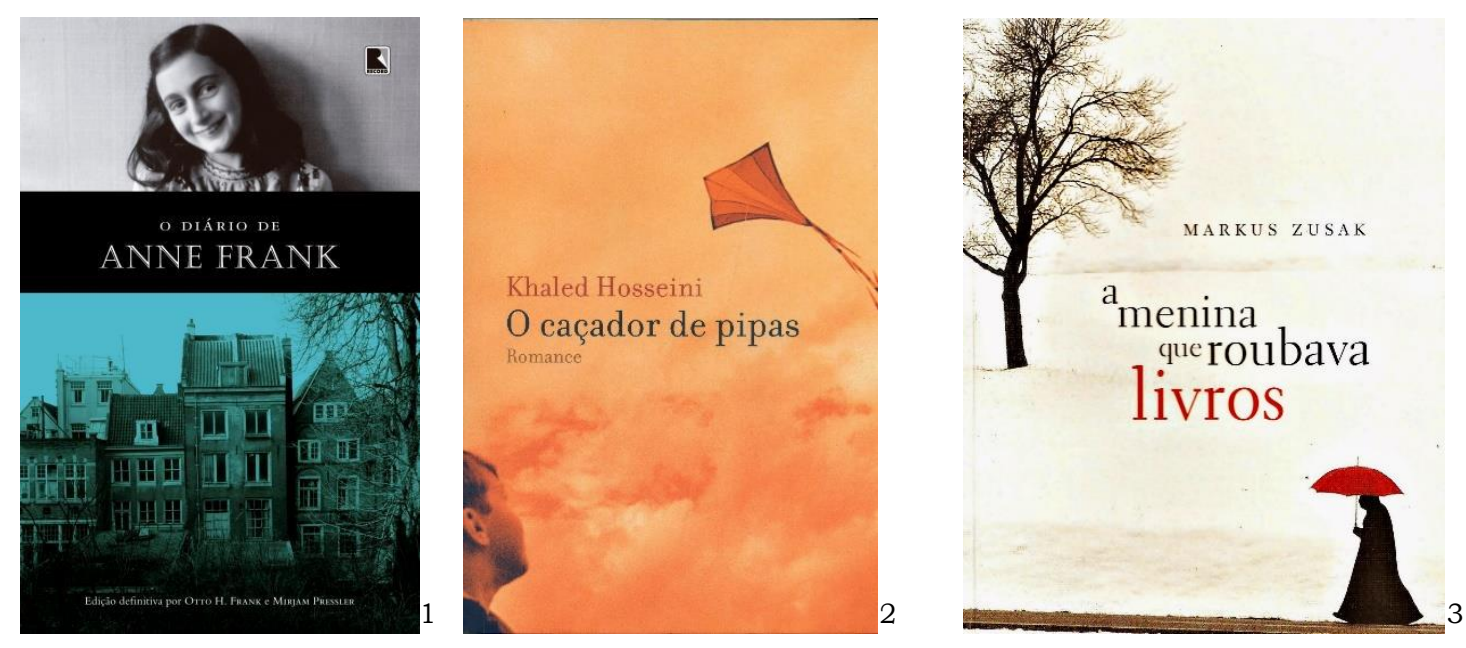

Com base no exposto, essa análise será feita através das condições oferecidas para o desenvolvimento do projeto e, em seguida, pelos registros etnográficos realizados pelos participantes no processo. Importante salientar que no primeiro encontro foi apresentado às reeducandas as diretrizes do projeto, como seria desenvolvido e a entrega dos livros que foram escolhidos pela coordenadora do projeto de acordo com o acervo da biblioteca do presídio.

A partir do segundo encontro começaram as oficinas e a apresentação das obras discutindo como seria desenvolvida a resenha final. O professorpesquisador salientou a importância de escreverem rascunhos para entenderem o processo de escrita e quais as características do gênero resenha. Devido ao tempo, o professor-pesquisador entregou o material didático produzido e pediu que lessem para que discutissem no encontro seguinte.

Os excertos escolhidos para análise referem-se ao terceiro encontro e apresenta o diálogo existente estre o professor-pesquisador e as reeducandas

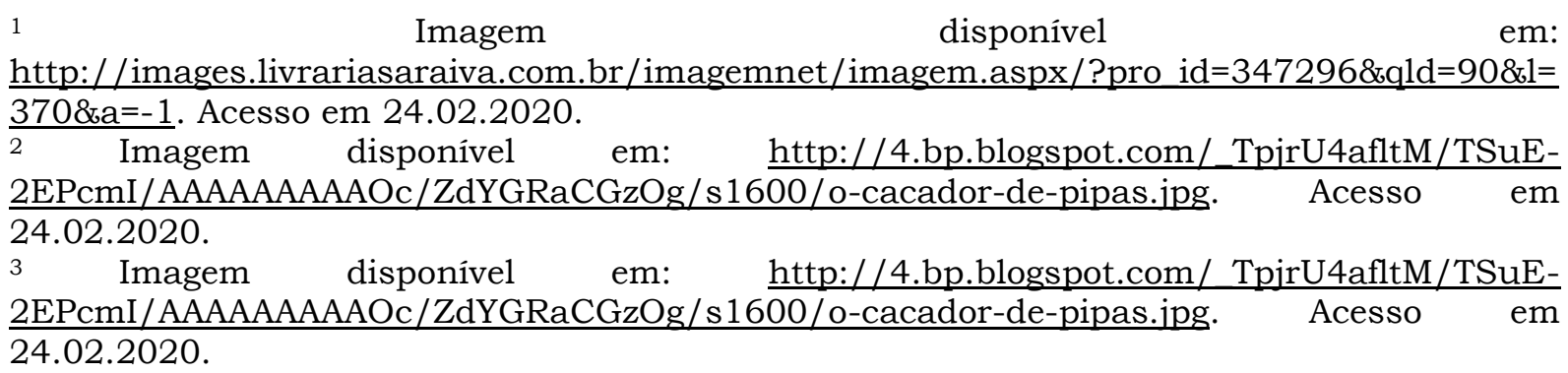


sobre a leitura dos livros que foram entregues no primeiro encontro, do material didático que seria estudado e do rascunho que elas começaram a fazer sobre o que estavam lendo. No excerto abaixo, vemos o diálogo entre o professor-pesquisador e das reeducandas no tocante ao material didático.

Excerto 01

\begin{tabular}{|l|l|}
\hline Reeducanda A & Atualmente estou sendo apresentada ao livro. \\
\hline $\begin{array}{l}\text { Professor- } \\
\text { Pesquisador }\end{array}$ & Não deixem de ler esse material. \\
\hline Reeducanda A & $\begin{array}{l}\text { Está demorando mais porque elas estão } \\
\text { demorando para liberar. }\end{array}$ \\
\hline $\begin{array}{l}\text { Professor- } \\
\text { Pesquisador }\end{array}$ & $\begin{array}{l}\text { Certo. Façam a leitura, nós vamos analisar a } \\
\text { característica da resenha de acordo com as } \\
\text { dúvidas. Ninguém mais poderá entrar no curso } \\
\text { para que possamos dar andamento. }\end{array}$ \\
\hline Reeducanda B & $\begin{array}{l}\text { O que é intencionalidade? Qual a intenção do livro } \\
\text { que estou lendo? A intertextualidade o que é? Isso } \\
\text { é intertexto? }\end{array}$ \\
\hline $\begin{array}{l}\text { Professor- } \\
\text { Pesquisador }\end{array}$ & $\begin{array}{l}\text { Vocês não precisam ter a resenha, mas os fatores } \\
\text { necessários para compor o tipo de que gênero que } \\
\text { são os aspectos importantes. O material que } \\
\text { entregamos para vocês é para auxiliar no trabalho } \\
\text { de vocês, no rascunho que precisarão fazer. Vamos } \\
\text { retomar rapidamente a aula passada. Vocês } \\
\text { trouxeram o material da aula passada? }\end{array}$ \\
\hline
\end{tabular}

Transcrição: Doutoranda A

A discussão parece estar pautada no material apresentado pelo professor-pesquisador acerca das características do gênero resenha. Ele evita as conversas paralelas que poderiam tirar o foco do objetivo da aula que era apresentar o material desenvolvido para as reeducandas. Para isso, elas precisariam ter lido o material. O ambiente de privação de liberdade produziu uma espécie de pedagogia do encarceramento, que priva as reeducandas do estímulo pelo perguntar, da liberdade de saber sobre o objeto de estudo apresentado e, ao mesmo tempo, é o espaço da contradição, porque ao solicitar a manutenção das normas, das regras, abre-se para as possibilidades - de interação, diálogo e de mudança. 
A opção do professor-pesquisador em se ater ao material didático apresentado parece indicar uma concepção de ensino tradicional, em que atua como o profissional preparado para instruir, transmitir os conhecimentos acumulados e sistematizados (SAVIANI, 2012, p. 06) cabendo às reeducandas assimilar o que está sendo transmitido disciplinarmente.

A identidade apresentada pelo professor-pesquisador se constrói, segundo Pimenta (2012), a partir da significação social e pelo significado que o professor, enquanto ator e autor confere à atividade docente, da sua história de vida, de suas representações, pois ao se constituir sócio-histórico e culturalmente em contextos situados, atribui determinados padrões de comportamento e atitudes.

Possivelmente, por encontrar-se em um ambiente de privação de liberdade, o professor-pesquisador ateve-se ao objetivo do projeto, mantendo distância inclusive das perguntas apresentadas. Aliado a esse aspecto, podese considerar o fato do professor-pesquisador ter mantido uma escuta ativa perante as diretrizes apresentadas pela Diretora e Coordenadora pedagógica do presídio em manter o distanciamento com as reeducandas.

O professor-pesquisador destaca para as reeducandas que não precisam ter a resenha, mas era necessário saber o plano global, os aspectos que compõem o gênero e, para isso, enfatiza a necessidade da leitura do material produzido. Esse procedimento utilizado pelo professor-pesquisador é alvo de inúmeras discussões acerca do ensino de língua portuguesa no Brasil, principalmente por ser evidente que as questões de ensinoaprendizagem ainda se encontram pautadas no ensino da gramática, nas regras, com poucas conexões com a realidade vivenciada pelos (re)educandos.

Essa forma de ensino tradicional e mecanicista apoia-se, frequentemente, no uso de algum material didático e de exercícios de fixação, pois o interesse é desenvolver a habilidade de falar e escrever de modo corretos, sem que ocorra, necessariamente, uma reflexão crítica sobre o objeto de ensino (AZEREDO, 2007). Esse tipo de educação bancária, na visão freireana, estabelece uma relação vertical entre professor e Interfaces da Educ., Paranaíba, v.11, n.32, p. 466 - 488, 2020 
(re)educando, com conteúdos desligados da prática social dos envolvidos no processo de ensino-aprendizagem. Em continuidade, o próximo excerto evidencia a aula preparada de acordo com o material produzido.

Excerto 02

\begin{tabular}{|l|l|}
\hline Reeducanda A & Não lemos o material \\
\hline Doutoranda A & $\begin{array}{l}\text { O pesquisador fez a leitura do material e escreve } \\
\text { na lousa: } \\
\text { As pessoas (as - artigo no plural) pessoas } \\
\text { (substantivo) }\end{array}$ \\
\hline $\begin{array}{l}\text { Professor- } \\
\text { Pesquisador }\end{array}$ & $\begin{array}{l}\text { O que é um substantivo? Ele nomeia as coisas, } \\
\text { pessoas, cidades, garrafa... } \\
\text { O que é coerência textual? - Ela estabelece } \\
\text { sentidos } \\
\text { Ex.: manga (fruta) / manga (camisa) então, } \\
\text { estabelece uma unidade de sentido. }\end{array}$ \\
\hline Reeducanda B & Você fala da capa né? \\
\hline $\begin{array}{l}\text { Professor- } \\
\text { Pesquisador }\end{array}$ & $\begin{array}{l}\text { Da capa, da imagem, do que está dentro do livro, } \\
\text { tudo estabelece uma coerência de sentidos. }\end{array}$ \\
\hline
\end{tabular}

Transcrição: Doutoranda A

Diante da colocação da reeducanda de que não leram o material produzido, o professor-pesquisador passou a usar a lousa para explicá-lo. Mais uma vez, observa-se o distanciamento com as reeducandas. Não houve questionamentos sobre o fato de não lerem o material, das possiveis dúvidas das reeducandas. Street (2014) argumenta que concepções dominantes de letramentos, especialmente as voltadas para leitura e escrita, são construídas e reproduzidas de modo a marginalizar outras práticas educativas de (multi)letramentos que possam auxiliar e tornar o (re)educando como agente no processo de ensino-aprendizagem.

Vemos que o professor-pesquisador instrumentaliza a lingua, o que revela sintonia nas discussões apresentadas por Street (2014) ao argumentar que, ao se objetificar a lingua na escola, estamos tratando-a como algo externo aos (re)educandos e a si mesma, como se adquirisse qualidade autônoma, não social, e que se impõe aos seus usuários, no uso 
de regras e normas gramaticais, um distanciamento entre os usuários e a língua. Nessa perspectiva, o (re)educando ao apresentar dificuldade na leitura e na escrita, dificilmente poderá se engajar em contextos sociais mais amplos.

Em sintonia com o autor, o modo como o processo de ensinoaprendizagem estava acontecendo ajudava a construir o distanciamento entre as reeducandas e o professor-pesquisador, já que a lousa serviu como técnica que permitiu às reeducandas objetificar esse processo de aprendizagem. Ademais, concordamos com Street (2014) quando apresenta que uma vez na lousa, na folha de exercícios, a língua passa a ser um problema à parte, sobre o qual os envolvidos passam a trabalhar em conjunto para resolvê-lo.

É importante lembrar que nos encontrávamos apoiados em Moita Lopes (2006), no sentido de pensar a linguística aplicada em diálogo interdisciplinar com os campos de ciências sociais e humanas, para criar inteligibilidade sobre os problemas sociais em que a linguagem tem papel central (MOITA. LOPES, 2006, p.14) e na transdisciplinaridade, como movimento de interação entre as ciências (CELANI, 2004, p. 132), com foco na construção do conhecimento transdisciplinar, mais globalizador. Transdisciplinar porque está ao mesmo tempo entre as disciplinas, através das disciplinas e além de toda disciplina (NICOLESCU, 1999; 2003), pois busca compreender o presente manifesto para (re)construir um pensamento complexo (MORIN, 2007).

Soma-se a esses aspectos o fato de estarmos aliados ao conceito dos multiletramentos (GNL, 1996), na perspectiva de considerar o contexto, a prática situada das reeducandas, de torná-las agentes no processo de ensino-aprendizagem, na interação dialógica entre os envolvidos e, ao verificarmos que essa construção ocorreu de maneira mais mecanicista, verticalizada e distante da realidade das reeducandas, solicitou um olhar crítico dos envolvidos no projeto, Coordenadora e Doutorandos, no final deste encontro. 
No encontro seguinte, antes do início da aula, a coordenadora pedagógica do presídio pede um momento ao professor-pesquisador para conversar com as reeducandas sobre uma possivel prática de venda de resenhas que estava ocorrendo no presídio. Vejamos o excerto.

Excerto 03

\begin{tabular}{|l|l|}
\hline Doutoranda B & $\begin{array}{l}\text { A coordenadora entrou na sala de aula e pediu } \\
\text { para fazer a chamada e dar alguns avisos. Ela } \\
\text { comentou sobre o beneficio do projeto, que além } \\
\text { da remição é um momento de aprendizagem, de } \\
\text { conversar, de construir, de se posicionar, se têm } \\
\text { noção disso? }\end{array}$ \\
\hline Coordenadora & $\begin{array}{l}\text { Sabem da importância? Vocês sabem que está } \\
\text { rolando uma conversa de que tem alguém } \\
\text { vendendo resenha? Se eu souber quem, vai ter } \\
\text { punição. É preciso respeitar o trabalho } \\
\text { desenvolvido pelos pesquisadores e vocês também. } \\
\text { Eu não estou acusando, estou avisando que isso } \\
\text { pode estar acontecendo. Não disse que é desta } \\
\text { turma, mas estou avisando. }\end{array}$ \\
\hline $\begin{array}{l}\text { Professor- } \\
\text { Pesquisador }\end{array}$ & $\begin{array}{l}\text { É algo construído. Não pode ser comprado. E se } \\
\text { alguém estiver vendendo a errada? Vocês vão cair } \\
\text { no conto do pato. Tenho certeza de que todas } \\
\text { vocês conseguem. }\end{array}$ \\
\hline Coordenadora & $\begin{array}{l}\text { Tudo certo? Conversamos. Fechamos esse } \\
\text { assunto. }\end{array}$ \\
\hline
\end{tabular}

Transcrição: Doutoranda B

A coordenadora pedagógica do presídio relata da importância do projeto para as reeducandas, de aproveitar o momento de aprendizagem, construção e de tomar posição. Todavia, relata que a prática de venda de resenha parece estar ocorrendo e, caso alguém seja pego ou denunciado, haverá punição. O presídio é o lugar onde a presunção de inocência se esvai, deixa de existir, todas são culpadas e estão cumprindo a pena outorgada judicialmente, no processo.

Foucault (1999) salienta que a prisão priva o indivíduo de sua liberdade como direito e o corpo, ao ser colocado em um sistema de coação, Interfaces da Educ., Paranaiba, v.11, n.32, p. 466 - 488, 2020 
privação, obrigações e interdições, passa a ser manipulado à distância, segundo regras rígidas e visando objetivos mais elevados. Ao violarem o código de condutas e regras do sistema prisional, o corpo e a alma passam por punições, pois a instituição conhece o passado e o crime que realizaram e projetam o que se pode esperar desse indivíduo não apenas enquanto cumprem a pena, como também no futuro (FOUCAULT, 1999).

É certo que não fica evidente qual o tipo de punição que as reeducandas sofreriam caso fosse descoberto quem vendia as resenhas, mas a vigilância em relação ao ato que, possivelmente, estavam realizando, mereceu o alerta da instituição. No sistema prisional, a punição tem como função tornar o criminoso capaz de respeitar a lei e, ao fazê-lo, controla o corpo, neutraliza o indivíduo e as suas ações, mantendo a ordem. Ao obedecerem, a infração cometida pode ser modificada. No caso das reeducandas, pode-se considerar que elas continuariam no projeto de remição de pena pela leitura e escrita do gênero resenha.

Para a administração do presídio, o objetivo central era a realização das resenhas pelas reeducandas. Não é admitida a venda de textos e constitui-se uma infração com punição. Consideramos o aviso da administração como se encontrando em vigilância, atentos aos acontecimentos. Além disso, é certo que o sistema coercitivo prisional direciona o aviso não apenas para as reeducandas, mas também para os participantes do projeto, como forma de revermos a condução das oficinas.

O professor-pesquisador, por sua vez, ressalta que a resenha é um texto construído e que todas as reeducandas conseguem escrever seu próprio texto. De fato, a construção do conhecimento é algo construído, tecido entre todos os envolvidos no processo de ensino-aprendizagem e diante das discussões apresentadas, busca-se a superação dos problemas detectados. Ao descobrirmos a possivel venda das resenhas, revelou-nos a necessidade de refletirmos sobre nossas ações pedagógicas de modo a rever como poderíamos contribuir significativamente para uma educação mais autônoma, como prática de liberdade. 
A análise realizada dos aspectos das condições oferecidas e dos dados coletados revelaram que o projeto piloto serviu como importante instrumento de aprendizagem, pois ficamos cientes de que devemos levar para a sala de aula situações concretas das vidas das reeducandas, compreender melhor a prática situada em que se encontram, para buscar na concepção crítica dos envolvidas uma prática transformadora no agir e pensar de todos os envolvidos no projeto de remição de pena.

Atitudes como a compra de livros comuns para todas as reeducandas fez parte da nossa análise, pois três exemplares tornaram mais complexos o desenvolvimento das ações pedagógicas. Um aspecto importantíssimo foi a nossa reflexão crítica sobre a ação pedagógica desenvolvida no projeto. Somos contra a concepção bancária, baseada unicamente na língua escrita, no distanciamento entre os envolvidos, ancorada nos aspectos formais da lingua e que, visivelmente, contrariam a proposta do projeto, já que buscamos na reflexão crítica, um comprometimento em busca de uma cidadania desejável.

Em razão dessa experiência com o projeto piloto, ficou evidente a necessidade de revisitarmos nossa formação acadêmica, conceitos, crenças, valores, postura de resistência ocorrida entre os participantes do projeto. $\mathrm{O}$ distanciamento inicial entre professor-pesquisador e reeducandas estabeleceu algumas barreiras que refletiram no desenvolvimento das oficinas e dos objetivos do projeto. Estar em um sistema carcerário não significa desempenhar uma pedagogia carcerária. Pelo contrário, em contextos de privações, de extrema complexidade e punições, torna-se possivel pensar-agir em prol de uma cidadania mais desejável.

\section{Considerações Finais}

Concluindo, entendemos que a pesquisa de Extensão em desenvolvimento terá grandes impactos na formação de uma cidadania das reeducandas, pois trabalharemos com atividades desejáveis ancoradas em valões éticos concernentes ao respeito a si mesmo e aos outros. Apoiando- 
nos em Diniz (2014:1) esperamos que nosso trabalho de extensão possibilite que as reeducandas sejam

1. "conscientes de si e dos outros, ou seja, seres capazes de reconhecimento da existência do "outro" como iguais a eles, sem pré-juízos ou preconceitos;

2. capazes de orientar sua vontade e decidir entre várias alternativas, ou seja, ser dotados de visão critica que lhes permita fazer escolhas segundo sua vontade, e não segundo manipulações massificadoras;

3. responsáveis, isto é, ter a capacidade para avaliar os efeitos de suas ações sobre si mesmos e sobre os outros, respondendo às suas consequências;

4. livres, não para escolher entre alternativas dadas, mas para se autodeterminarem usando o beneficio da dúvida como instrumento de um conhecer permanente e inacabado".

O projeto piloto mostrou-nos os desafios que é proporcionar educação em contexto de privação de liberdade. Deixou-nos, em diversos momentos, preocupados em como desenvolver espaços para pensar em uma cidadania desejável, ética, respeito ao outro como ato consciente, já que vivenciávamos a vigilância constante, as regras, as punições, o enquadramento dos gestos, das condutas, da ocupação do corpo e do tempo (FOUCAULT, 1999) das reeducandas. Precisávamos repensar a postura in- e transdisciplinar que nos ancorava e, para isso, considerar os aspectos sócio-histórico e culturais das reeducandas para o desenvolvimento das oficinas de modo transformador era fundamental.

Educar solicita o diálogo aberto, a postura transgressiva (PENNYCOOK, 2006) capaz de transpor fronteiras, os limites do pensamento e das ações tradicionais para um posicionamento reflexivo, crítico, para a mudança. Essa postura transgressiva nos fez perceber a necessidade de pensar em promover espaços de formação de professores para atuarem em contexto de privação de liberdade, nas dificuldades encontradas ao propor situações de aprendizagem em espaços onde a vigilância e a punição são 
constantes e o preconceito para com as reeducandas acontece todos os dias por terem violado a lei.

Enfim, esses obstáculos foram necessários para revermos a nossa concepção de mundo, de liberdade, de crenças e valores, de modo a olharmos para a educação como prática transformadora e as reeducandas como agentes do mundo. E, como todo ato educativo é um ato de humanização, conforme Arendt (1998), esperamos que as reeducandas reflitam sobre a validade do conhecimento partilhado, ressignifiquem o que aprenderam e (re)construam para a vida.

\section{Referências}

ARENDT, H. Entre o passado e o Futuro. São Paulo: Perspectiva, 1988.

AZEREDO, J. C. de. Ensino de português: fundamentos, percursos, objetos. Rio de Janeiro: Jorge Zahar, 2007.

CELANI, M. A. Transdisciplinaridade na Linguística Aplicada no Brasil. In: SIGNORINI. I; CAVALCANTI, M. (ORG.). Linguística Aplicada e Transdisciplinaridade: questões perspectivas. Campinas, SP: Mercado de Letras 1998.

CHIZZOTTI, A. Pesquisa em ciências humanas e sociais. 5. ed. São Paulo: Cortez, 2001.

COPE, B. \& KALANTZIS, M. Multiliteracies - Literacy Learning and the Design of Social Futures. London; New York: Routledge, 2000.

DENZIN, N. K. e LINCOLN, Y. S. Introdução: a disciplina e a prática da pesquisa qualitativa. In: DENZIN, N. K. e LINCOLN, Y. S. (Orgs.). O planejamento da pesquisa qualitativa: teorias e abordagens. Porto Alegre: Artmed, 2006. p. 15-41.

DINIZ, D. Reflexões sobre o ato de educar: educação e humanização. Revista Educação Pública. 2014. https://educacaopublica.cecierj.edu.br/artigos/14/37/reflexes-sobre-o-ato-deeducar-educao-e-humanizao

FERNANDES, A. V. e PALUDETA, M. C. Educação e Direitos Humanos: Desafios para a escola contemporânea. Caderno Cedes. Campinas, vol 30, n. 81, p.233-249 Mai-ago.2010.

FOUCAUlT, M. Vigiar e Punir: nascimento da prisão. Trad. Lígia M. Ponde Vassalo. 20 ed. Petrópolis: Vozes, 1999. 
GENTILI, P. Educar na Esperança em tempos de desencanto. In: GENTILI, P. \& ALENCAR, C. Educação e Cidadania: A Formação ética como desafio político. Petrópolis: Editora Vozes. 2001.

KINCHELOE, J. L., \& MACLAREN, P. Rethinking Critical Theory and Qualitative Research. In N. K. Denzin \& Y. S. Lincoln (Eds.), The Sage handbook of qualitative research (pp. 303-342). THOUSAND OAKS, CA, : SAGE PUBLICATIONS LTD. 2005.

MOITA LOPES, L. P. Linguística Aplicada e Vida Contemporânea: Problematização dos Construtos que têm orientado a pesquisa. In: MOITA LOPES, L. P. (Org.). Por uma Linguística Aplicada Indisciplinar. São Paulo: Parábola Editorial, 2006.

MORIN, E. Ciência com consciência. Rio de Janeiro : Bertrand, 2007.

NEW LONDON GROUP. A pedagogy of multiliteracies: designing social futures. The Harvard Educational Review, v. 1, n. 66, p. 60-92, 1996.

NICOLESCU, B. O manifesto da Transdisciplinaridade. São Paulo: Triom, 1999.

Definition of transdisciplinarity. 2003. Disponivel em: <http://www.interdisciplines.org/interdisciplinatity/papers $>$. Acesso em: 18 mai. 2020.

ONOFRE, E. M. C. Educação escolar para jovens e adultos em situação de privação de liberdade. Caderno Cedes, Campinas, v. 35, n. 96, p. 239-255, nov/ago 2015.

ONOFRE, E. M. C. \& JULIÃO E. F. A educação na prisão como politica pública: entre desafios e tarefas. Educação e Realidade, Porto Alegre, v. 38, n. 1, p. 51/69. Jan/mar 2013.

PENNYCOOK, A. Uma linguística aplicada transgressiva. In: MOITA LOPES, Luiz Paulo (Org.). Por uma linguística indisciplinar. São Paulo: Parábola Editorial, 2006, p. 67-84.

PIMENTA, S. G. Formação de professores: identidade e saberes da docência. In: PIMENTA, S. G. (Org.). Saberes pedagógicos e atividade docente. 8a ed. São Paulo: Cortez, 2012. p. 15-34.

SAVIANI, D.; DUARTE, N. (Orgs.). Pedagogia histórico-crítica e luta de classes na educação escolar. Campinas: Autores Associados, 2012.

SIGNORINI, I. A questão da língua legítima na sociedade democrática; um desafio para a linguística aplicada contemporânea. In: Por uma Linguística Aplicada Indisciplinar. São Paulo: Parábola Editorial, 2006.

STREET, B. V. Letramentos sociais: abordagens críticas do letramento no desenvolvimento, na etnografia e na educação. Trad. Marcos Bagno. São Paulo: Parábola, 2014. 